\title{
Chemical recycling of polyethylene terephthalate (waste water bottles) for improving the properties of asphalt mixture
}

\author{
Mohammed Alzuhairi ${ }^{1, *}$, Ahmed Al-Ghaban ${ }^{1}$, Shams Almutalabi ${ }^{1}$ \\ Department of Materials Engineering, University of Technology, Baghdad, Iraq
}

\begin{abstract}
One of the most prevalent of waste materials is Polyethylene Terephthalate (PET) which is used mainly to produce the drinking water bottles. In this research, the waste plastic bottles, which are normally made from PET was used to investigate the possibility of using this material as an additive in asphalt concrete mixtures. Six different proportions (w/w \%) of Degradated Polyethylene Terephthalate (DPET) (2, $4,6,8,10$, and $12 \%$ ) have been added to bitumen to prepare the specimens. The tests include Marshall Method of mix design and coating with asphalt. The results indicated that the mixture property modification increased as the content of (DPET) increases. This additive gives maximum flexibility and rigidity of the asphalt, according to ductility and penetration tests. Marshall Method gives better resistance against permanent deformations and better engineering properties in terms of stability, flow value, air voids and water absorption comparing with non-modified mixtures.
\end{abstract}

\section{Introduction}

Plastic is a commonly available material which is used widely all over the world and it has many advantages such as: Lightweight, flexibility, robustness and rigidity. Although it is used in different applications like bags, food packages, containers and bottles, the problem raised here is how to get rid of it after use, because it's made of polymer chemicals which are not biodegradable. Polymers can be divided into two major classifications including thermoplastic materials (foams, adhesives, embedding resins and elastomers) and thermosetting materials (or Thermosets) [2]. Plastic is also an inexpensive, lightweight and durable material, which can easily be molded into a variety of products that can be found use in a wide range of applications. As a result, the production of plastics has increased significantly over the last 60 years [3]. Several possible ways to get rid of plastics have been investigated. Recycling is one of these methods. It involves processing of plastic materials (waste) to turn them into new materials as an essential way to keep environment green. The new product of recycled plastics can be used as an additive. The plastic addition to bitumen in the road construction has increased its smoothness and lifespan and also makes it environment friendly and economical. Plastic waste is used as a modifier of asphalt to enhance many properties of asphalt roads. Plastic water bottles, that are mainly made from Polyethylene Terephthalate (PET), though do not have any direct danger on the environment, but because of the large quantities of plastic waste dumped in the environment and the sea, it would be a serious problem to the environment[4].
From the environmental and sustainability point of view, chemical recycling is the most suitable process because, in chemical recycling operations, new raw materials are produced that in turn can be reused again in the production of chemical and in petrochemical or refineries. It is also a partial solution to the solid PET waste issue [5].

There are different ways to improve asphalt mixture properties, first is constructing road pavement of higher thickness, the second is using different types of additives as a modifier (e.g. different types of fibers and polymers) in the asphalt mixture. Constructing high-thickness pavement will cause considerably higher construction cost. Thus, using additives might be a better solution to overcome the pavement deterioration problem [6].

In recent years, a serious environmental problem due to the amount of waste plastic bottles is increasingbeing increased steadily and has become a global problem. So, the world focuses on solving this problem by many methods such as recycling. It is one of the most important efforts currently available to reduce this problem by providing opportunities to reduce the use of oil, carbon dioxide emissions and the quantity of waste that requires disposal. This work aims at:

- Analyzing the effect of additive degraded PET on the properties of mixed asphalt for road paving and coating applications.

- Studying the effect of temperature on the mechanical and physical properties of modified asphalt and finding the optimum percentage of plastic waste (PET) through making comparison between conventional and modified asphalt.

\footnotetext{
* Corresponding author: dr.alzuhairi@gmail.com
} 
This research is very important in many ways - one of them is the recycle of tens of thousands of tons used for asphalt improving and second - it is a creative method for chemical degradation of PET in a simple and low cost manner.

\section{Materials}

\subsection{Bitumenous}

The asphalt used in this research is petroleum asphalt brought from Al-Obaidy asphalt plant, refined at 40/50 penetration-grade asphalt cement was used for this investigation. Hot mix asphalt (HMA) used in this work is available in large quantities locally in Iraq. The properties of asphalt binder based on the values of Iraqi specification for Roads and Bridges (2016) [7].

\subsection{Aggregates}

Aggregates are the main material in the asphalt mixture. The crushed coarse and fine aggregates were brought from Al -Nibaee quarry in the north of Baghdad; the coarse aggregate consists of strong, hard, durable pieces. According to specification (2016)[7] the gradation of coarse type aggregate ranges between $3 / 4$ in. $(19.0 \mathrm{~mm})$ and No.4 sieve $(4.75 \mathrm{~mm})$. While the gradation of fine type aggregate ranges between $4.75 \mathrm{~mm}$ (No.4) sieve and $0.075 \mathrm{~mm}$ (No.200) sieve.

Tabel 1. Properties of asphalt (bitumen) binder of alobeidi asphalt plant*.

\begin{tabular}{|l|l|l|l|}
\hline Test & ASTM & \multicolumn{2}{|l|}{ Specification } \\
\cline { 3 - 4 } & & Min & Max \\
\hline Penetration (0.1 mm) & ASTM D5 & $40 \mathrm{~mm}$ & $50 \mathrm{~mm}$ \\
\hline Ductility (cm) & $\begin{array}{l}\text { ASTM } \\
\text { D113 }\end{array}$ & $>100$ & $<100$ \\
\hline $\begin{array}{l}\text { Flash \& Fire Point } \\
\left({ }^{\circ} \mathrm{c}\right)\end{array}$ & ASTM D 92 & 175 & 250 \\
\hline $\begin{array}{l}\text { Ring \& Ball } \\
\text { Softening Point }{ }^{\circ} \mathrm{C}\end{array}$ & ASTM D36 & 50 & 60 \\
\hline $\begin{array}{l}\text { Specific Gravity } \\
\text { Viscosity at 135 }{ }^{\circ} \mathrm{C}\end{array}$ & $\begin{array}{l}\text { ASTM D70 } \\
\text { D2170 }\end{array}$ & 1.01 & 1.06 \\
\hline $\begin{array}{l}\text { *These tests had been done in asphalt technology laboratory, } \\
\text { University of Technology. }\end{array}$ & & & \\
\hline
\end{tabular}

The fine type consists of tough grains free of clay, loam or other deleterious materials. The physical properties of Al-Nibaee aggregate listed in the table (2).

\subsection{Filler}

The filler used consists of Portland cement and limestone powder, these fillers added to hot mix asphalt, to increase the density and strength of the mixture. These fillers should pass through $75 \mu \mathrm{m}$ SI sieve (International System of Units), as shown in Table 3.

Tabel 2. Physical properties of al-nibaee aggregates*.

\begin{tabular}{|l|l|l|l|}
\hline Property & ASTM & $\begin{array}{l}\text { Coarse } \\
\text { Aggregate }\end{array}$ & $\begin{array}{l}\text { Fine } \\
\text { Aggregate }\end{array}$ \\
\hline $\begin{array}{l}\text { Bulk Specific } \\
\text { Gravity }\end{array}$ & ASTM C127 & 2.646 & 2.63 \\
\hline $\begin{array}{l}\text { Apparent } \\
\text { Specific } \\
\text { Gravity }\end{array}$ & ASTM C127 & 2.656 & 2.667 \\
\hline $\begin{array}{l}\text { Percent Water } \\
\text { Absorption }\end{array}$ & ASTM C127 & 0.47 & 0.523 \\
\hline $\begin{array}{l}\text { Percent Wear } \\
\text { (Los-Angeles } \\
\text { Abrasion) }\end{array}$ & ASTM C131 & 22.69 & $\ldots \ldots$. \\
\hline
\end{tabular}

*These tests were made by the national center for construction labs and researches in Baghdad/Iraq, as well as table (3).

Tabel 3. Physical properties of cement and limestone*

\begin{tabular}{|l|l|}
\hline Filler & \multicolumn{1}{|c|}{ Specific Gravity } \\
\hline Cement & 3.12 \\
\hline Limestone & 2.73 \\
\hline
\end{tabular}

\subsection{Water bottles (PET)}

In this study the waste plastic water bottles (PET) were added as a modifier of asphalt to achieve a service life of road pavement. It is cut into many small sized pieces. This material is present everywhere in huge quantities due to its wide use and low cost. This research includes adding Ethylene Glycol (EG), which was used as a solvent for glycolysis and zinc acetate particles were used as a catalyst acting as an analytical reagent grade to PET. Table (4) shows the properties of waste plastic, and Table (5) shows the main properties of ethylene glycol and zinc acetate [8].

Tabel 4. Properties of waste (PET).

\begin{tabular}{|c|c|c|}
\hline Density & Melting point & Molar weight \\
\hline $1.38 \mathrm{~g} / \mathrm{cm}^{3}, 20{ }^{\circ} \mathrm{C}$ & $260^{\circ} \mathrm{C}$ & $192.2 \mathrm{~g} / \mathrm{mol}$ \\
\hline
\end{tabular}

Tabel 5. Ethylene glycol \& zinc acetate properties (purity

\begin{tabular}{|l|c|c|c|}
\multicolumn{1}{|c|}{ Material } & Producer & M. Wt. & $P, \mathrm{~g} / \mathrm{cm}^{3}$ \\
\hline Ethylene Glycol & Barcelon (Spain) & 62.07 & 1.1132 \\
\hline Zinc Acetate & $\begin{array}{c}\text { Sigma Aldrich } \\
\text { (Germany) }\end{array}$ & 219.5 & 1.735 \\
\hline
\end{tabular}

\section{Experimental work}

\subsection{Close system}

In the first step, mixture of $100 \mathrm{gm}$ of PET, $116 \mathrm{ml}$ of ethylene glycol (EG.) (4:1, EG: PET, molar ratio) with $0.5 \%$ zinc acetate based on the weight of PET as catalyst were heat treated at $190^{\circ} \mathrm{C}$ for 5 hours until the mixture came in the resin state. Heat treatment involves complete condensation (reflux) of rising vapors in close system-no material is lost, through use of glass condenser which 
uses water as a cooler, then unreacted (EG) solution was separated from the previous mixture leaving behind the final form of the Degradated Polyethylene Terephthalate (DPET) as shown in Figure (1).

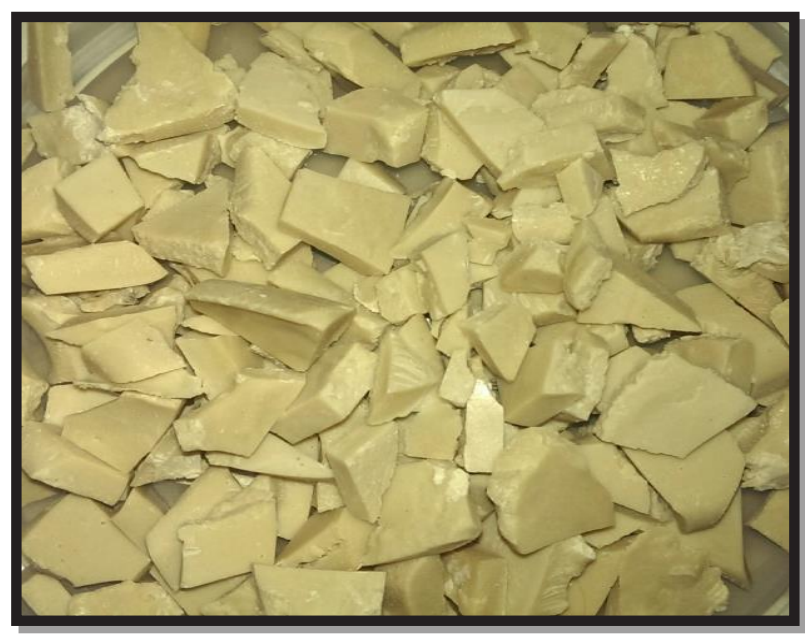

Fig. 1 Degradation of Polyethylene Terephthalate (DPET) after a liquid separation.

Close system of chemical recycling for PET is shown in Figure (2), with U-tube manometer above apparatus to ensure no loss of any vapors and materials from the system [9].

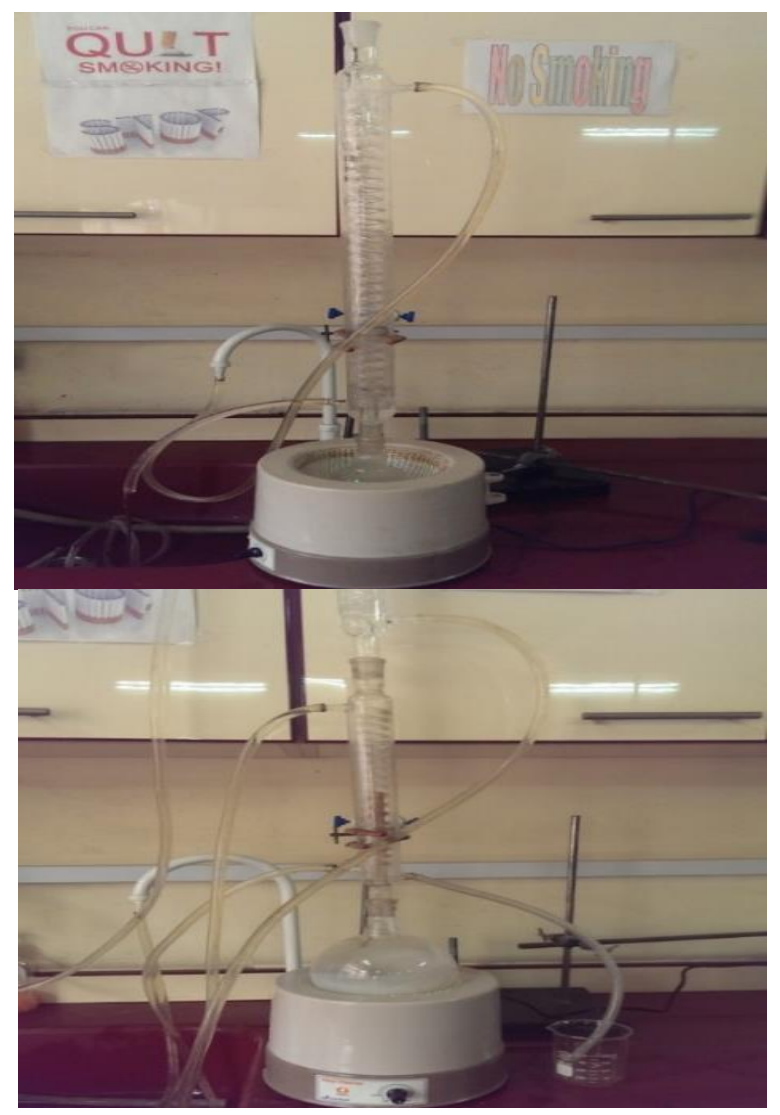

Fig. 2 Close system of chemical degradation.
In the second step, the product DPET, was mixed with bitumen by $(2,4,6,8,10$, and 12$)(\mathrm{w} / \mathrm{w} \%)$ at $200{ }^{\circ} \mathrm{C}$ for 2 hours, with mechanical mixing in 250 Revolution per Minute (RPM), as shown in the Figure (3). Finally product poured into a mold to cool at room temperature.

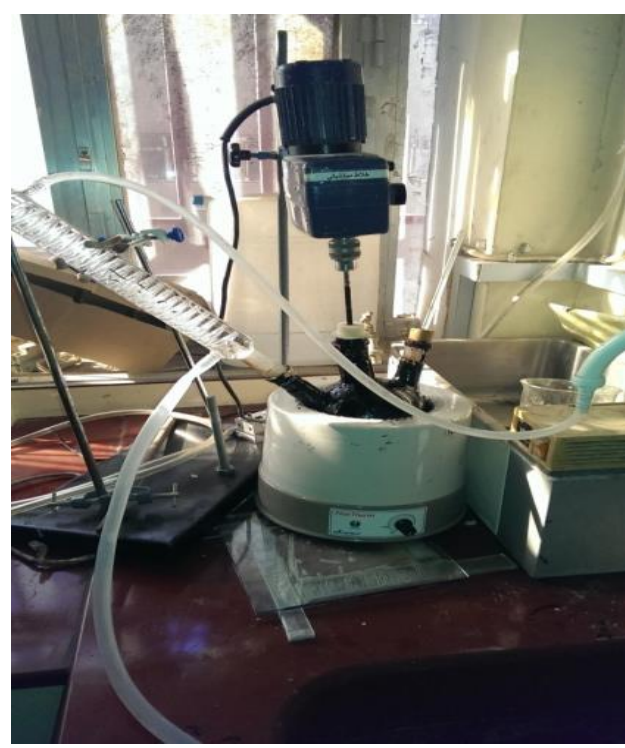

Fig. 3 Mechanical mixing of bitumen and DPET.

\subsection{Marshall mix design}

The grades of aggregates and their quantities used for preparing Marshall Samples were used according to Iraqi specification for Roads \& Bridges (2016). Suitably designed mix of bitumen will determine an economical blend through several trial mixes and resist the strong loads of traffic under negative environmental conditions such as (heavy rain, humidity and high temperature) also fit the characteristics of pavement surface and structure. This method determines the resistance to plastic flow within the cylindrical shape samples of bitumen paving mixture loaded on the lateral surface of Marshall apparatus according to ASTM (D1559) [ASTM, 2003]. This method includes preparing of cylindrical sample which is 2.5 inches $(63.5 \mathrm{~mm})$ in height, and (4 inches) $(101.6 \mathrm{~mm})$ in diameter. The optimum bitumen content was $(5 \%)$ by asphalt mix weight ${ }^{[10]}$. The samples of asphalt concrete mixtures of the additive type DPET were prepared to measure the adding effect of DPET to the mixture. The samples were prepared by the addition of six different percentages $(2,4,6,8,10$ and 12\%) added to the content of optimum asphalt. Three samples were measured for each proportion to determine the unit weight, flow and stability and air voids. The apparatus of this test includes: Marshall mold, compaction hammer, and spatula are heated on a hot plate to a temperature between (100-110) ${ }^{\circ} \mathrm{C}$, the procedure is done by applying the addition of DPET that mixed previously to the bitumen by mechanical mixture and placed into the oven 
and heated until it became liquid at (100-110) ${ }^{\circ} \mathrm{C}$, (45) minutes and heating $(1200 \mathrm{gm})$ of aggregates and filler of each sample until it reaches a $(160-180){ }^{\circ} \mathrm{C}$, then mixed together. The asphalt mixture was placed in the preheated mold, and it was then speculated mechanically for $15 \mathrm{~min}$ at $(150-170){ }^{\circ} \mathrm{C}$. Two filter papers were placed on the bottom of the mold filled with mixture in preparation to place the asphalt mix in the suitable mold. 72 blows were applied with the compaction hammer for each surface. After compaction was finished, the mold containing sample had to be cooled in air till enough cohesion had improved to result in the cylindrical proper shape, then the sample had to be extruded by a hydraulic jacking device to provide a constant and gentle pressure. Finally, samples immersed in a water bath at $60{ }^{\circ} \mathrm{C}$ ready for the test ${ }^{[10]}$.

\section{Results and discussion}

\subsection{The stability}

In this method, the stability values in asphalt mixtures are higher than the stability values in conventional mixture: the value in conventional mixture is $(12.1 \mathrm{KN})$ with filler cement, and $(9.6 \mathrm{KN})$ with filler dust limestone, while the maximum stability value at the added percentage of DPET (8\%) is found nearly (13.8 $\mathrm{KN})$ with filler cement, and $(11.8 \mathrm{KN})$ with filler dust limestone at $150^{\circ} \mathrm{C}$, Also the stability values in asphalt mixtures are higher than the stability value in conventional mixture: $(11.5 \mathrm{KN})$ with filler cement, and $(9.8 \mathrm{KN})$ with filler dust limestone, while the maximum stability value at the percentage $(8 \%)$ of DPET is found nearly $(14.7 \mathrm{KN})$ with filler cement, and $(11.9 \mathrm{KN})$ with filler limestone at $170^{\circ} \mathrm{C}$. This increase demonstrates that an improvement has been achieved with regard to the compressive strength of asphalt mixture as the percentages of DPET additions indicate, as shown in Figures (4) and (5). This shows that the results (0-12\%) of the additive are within the range of Iraqi specification for Roads and Bridges (2016) which determine the minimum value of stability test $(8 \mathrm{KN})$. DPET works to increase the viscosity, stiffness and hardness of the bitumen, which leads to reduction in penetration and softening point as mentioned above, and the Marshall value for the mixture with cement filler is higher than the value mixture with dust limestone because mixture gives high density and lower air voids.

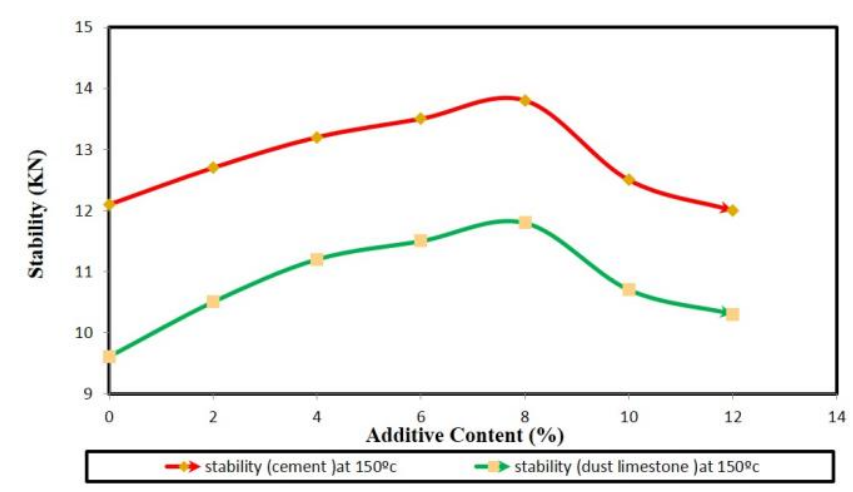

Fig. 4 DPET effects on Asphalt mixture stability at $\left(150{ }^{\circ} \mathrm{C}\right)$.

\subsection{The flow}

In the modified asphalt, the flow values in asphalt mixture are higher than those in a conventional asphalt mixture. The flow values decrease continuously as the DPET percentage increases, as shown in Figures (6) and (7). When adding \% DPET, the flow values extend from $(2.7 \mathrm{~mm})$ till they reach $(4.1 \mathrm{~mm})$ with the filler cement, while the flow values extend from $(3.2 \mathrm{~mm})$ till they reach $(4.8 \mathrm{~mm})$ with the filler dust limestone at $150^{\circ} \mathrm{C}$. But when the temperature is $170^{\circ} \mathrm{C}$, the flow values extend from $(2.9 \mathrm{~mm})$ till they reach $(4.2 \mathrm{~mm})$ the filler cement, while the flow values extend from $(3.7 \mathrm{~mm})$ till they reach $(4.8 \mathrm{~mm})$ with the filler limestone. All the results, were in the range of Iraqi specification for Roads and Bridges (2016) [the specification values extend from ( 2 to $4 \mathrm{~mm}$ )]. Flow increases that means the elastic behavior of the flow is related to the increase in ductility.

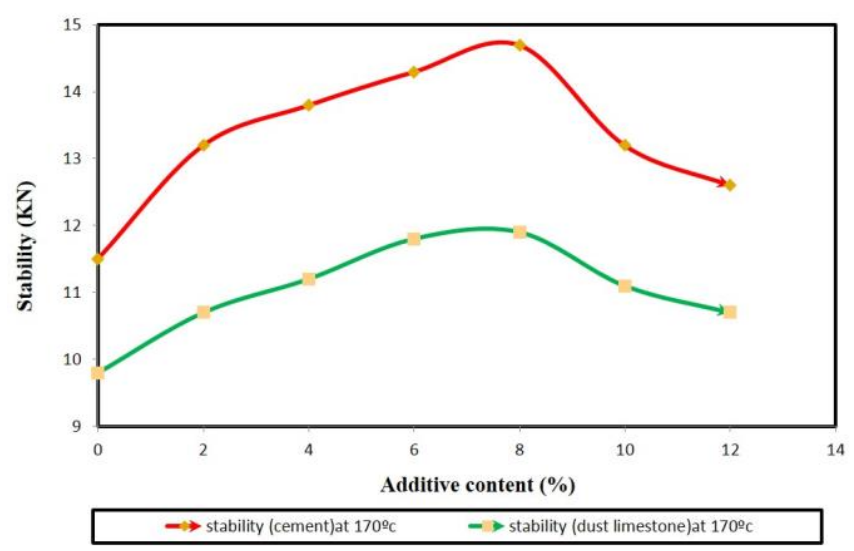

Fig. 5 DPET effects on Asphalt mixture stability at $\left(170{ }^{\circ} \mathrm{C}\right)$. 


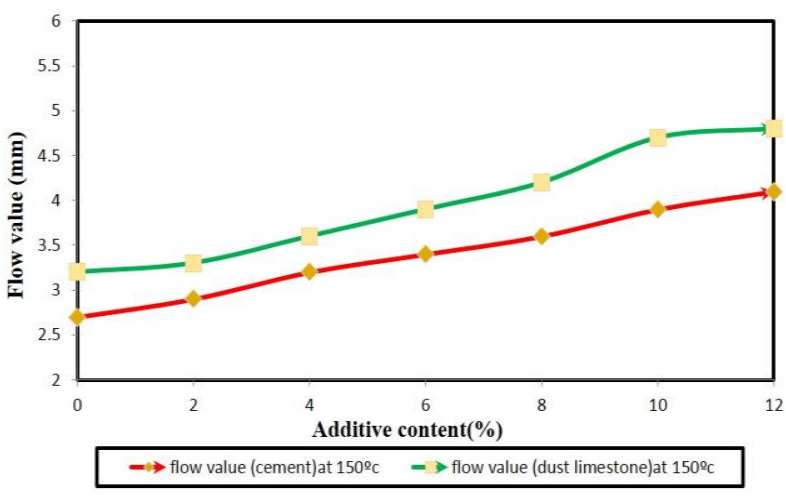

Fig. 6 DPET effects on Asphalt mixture flow at $\left(150^{\circ} \mathrm{C}\right)$.

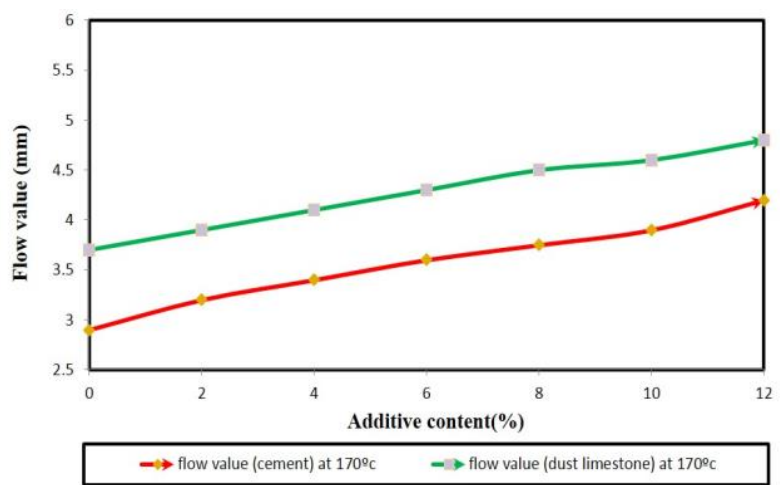

Fig. 7 DPET effects on Asphalt mixture flow at (170

\subsection{The bulk density}

The bulk density decreases as DPET content increases, when adding \% DPET, the bulk density values extend from $(2.32 \mathrm{~mm})$ till they reach $(2.278 \mathrm{~mm})$ with the filler cement, while the flow values extend from $(2.281 \mathrm{~mm})$ till they reach $(2.243 \mathrm{~mm})$ with the filler dust limestone at $150^{\circ} \mathrm{C}$. When the temperature is $170^{\circ} \mathrm{C}$, the flow values extend from $(2.38 \mathrm{~mm})$ till they reach $(2.32 \mathrm{~mm})$ with the filler cement, while the flow values extend from $(2.27 \mathrm{~mm})$ till they reach $(2.28 \mathrm{~mm})$ with the filler dust limestone. This decrease in bulk density is caused due to low density of PET added instead of asphalt, the effect of DPET in the asphalt mixture on the bulk density is shown in Figures (8) and (9). The results agree with the values of Iraqi specifications for Roads and Bridges (2016), which extend from (2.1 - $\left.2.45 \mathrm{gm} / \mathrm{cm}^{3}\right)$. Bulk

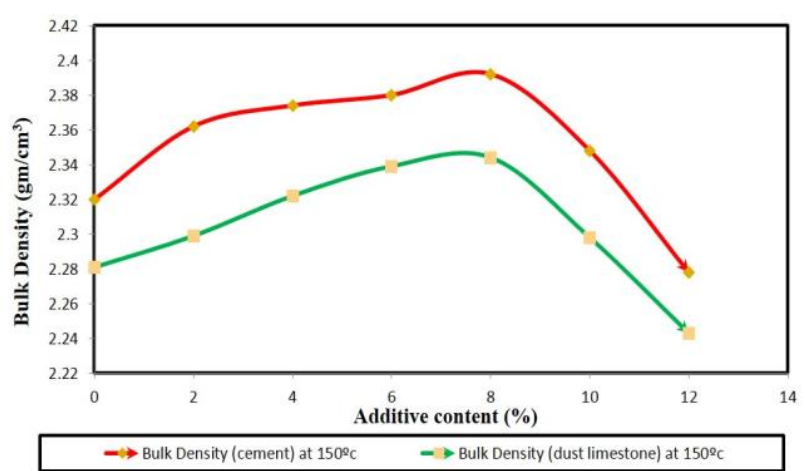

Fig. 8 DPET effects on bulk density of Asphalt mixture at (150 density of mixture with cement filler is higher than mixtures with dust limestone filler due to specific gravity of cement filler which is (3.12) and specific gravity of limestone filler which is (2.73), this difference in specific gravity values lead to this result.

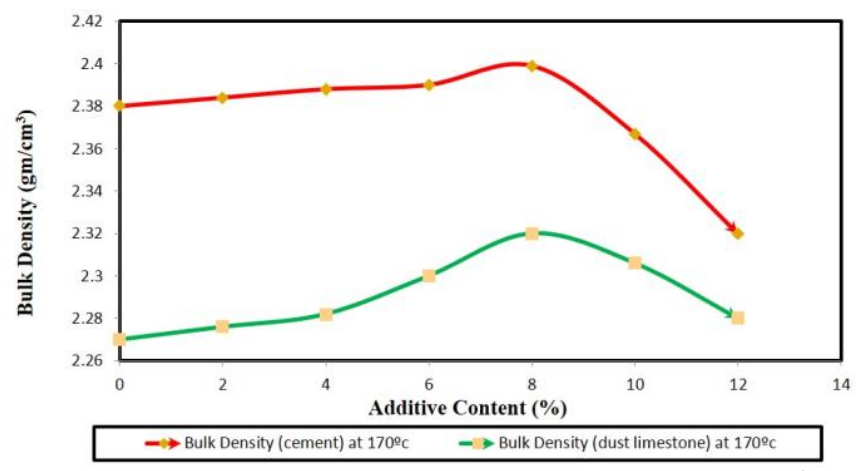

Fig. 9 DPET effects on bulk density of Asphalt mixture at $\left(170{ }^{\circ} \mathrm{C}\right)$.

\subsection{Air voids}

The percentages of air voids (during the addition method) decrease as DPET percentage increase, when adding \% DPET, the AV. values extend from $(6.2 \mathrm{~mm})$ till they reach $(3.4 \mathrm{~mm})$ with the filler cement, while the flow values extend from $(6.4 \mathrm{~mm})$ till they reach $(4.4$ $\mathrm{mm})$ with the filler dust limestone at $150^{\circ} \mathrm{C}$. When the temperature is $170^{\circ} \mathrm{C}$, the flow values extend from $(5.8$ $\mathrm{mm})$ till they reach $(4.2 \mathrm{~mm})$ with the filler cement, while the flow values extend from $(6.1 \mathrm{~mm})$ till they reach $(4.5 \mathrm{~mm})$ with the filler limestone, this decrease occurs due to increase in asphalt percentages which has a lower density than DPET, values of air voids with different DPET content percentages are shown in Figures (10) and (11) that deviate from the Iraqi specification for Roads and Bridges (2016) (values that extend from $3 \%$ to $5 \%$ ). Air voids in cement are less than those in dust limestone due to the high smoothness in cement as compared to the limestones, which consequently have effect the asphalt mixtures. Mixture with cement filler gives a high bulk density that leads to lower porosity due to high softness of cements.

\subsection{Coating tests (dilution)}

The diluents and mixture of bitumen \& DPET that meet concrete specifications consist of $30(\mathrm{v} / \mathrm{v})$ of toluene as the solvent for bitumen and DPET mixture. Toluene is an organic solvent, colorless with a special smell related to paint, thinners, one of the aromatic hydrocarbons which has density $0.87 \mathrm{~g} / \mathrm{cm}^{3}$, pb is $95^{\circ} \mathrm{C}$, and molar weight equal to $92.14 \mathrm{~g} / \mathrm{mol}$. Toluene widely used as substitute for gasoline is chemically toxic. It can be added to the fuel and used as an argument for a large number of compounds, including drugs, dyes, detergents, perfumes, explosives and synthetic resins $[10,11]$.

\subsection{Preparation of the samples}




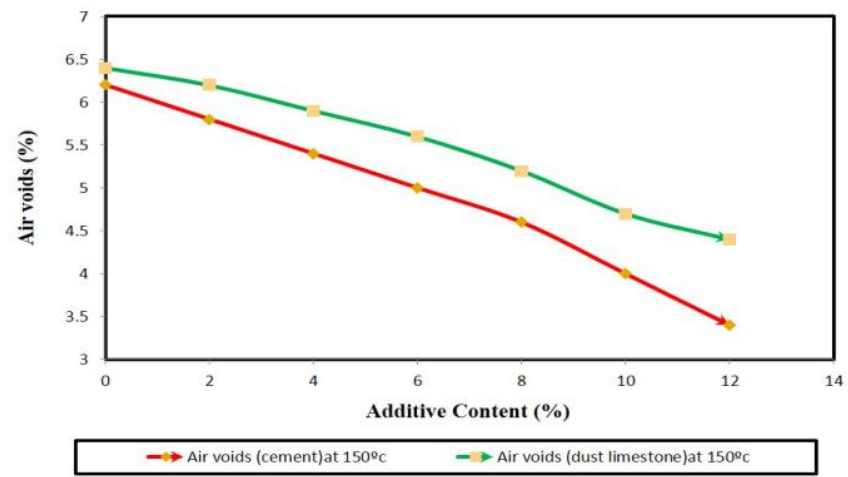

Fig. 10 DPET effects on air voids of Asphalt mixture at $\left(150{ }^{\circ} \mathrm{C}\right)$.

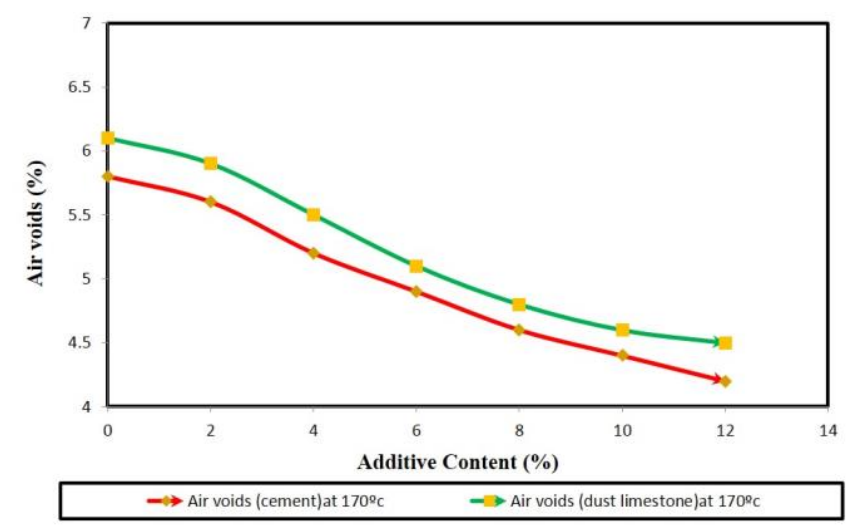

Fig. 11 DPET effects on air voids of Asphalt mixture at $\left(170{ }^{\circ} \mathrm{C}\right)$.

The different samples of concrete are prepared at $(1: 2.75)$ cement: sand with water cement ratio $(0.495)$ and composting size $(5 \mathrm{~cm} \times 5 \mathrm{~cm} \times 5 \mathrm{~cm})$ of the mold. Then, the concrete is repainted with the diluted bitumen and left in the air for three days to dry completely. Finally, the repainted concrete is immersed in water for seven days at different temperatures $(0,20,40$, and 60 $\left.{ }^{\circ} \mathrm{C}\right)$ to investigate the water absorption as shown in Figure (12).

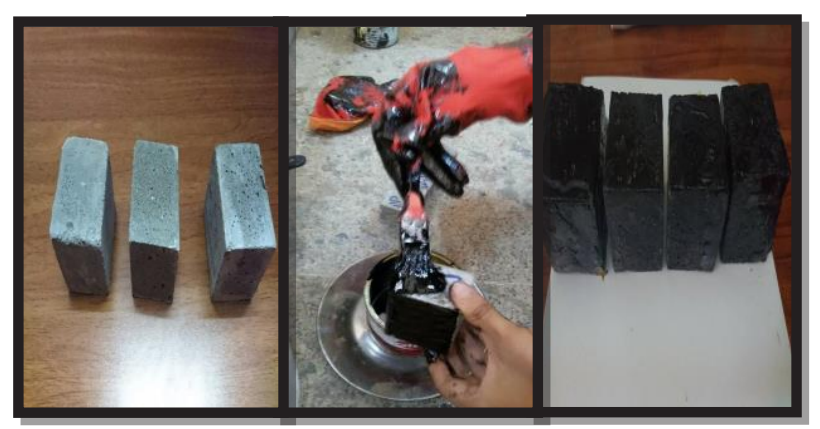

Fig. 12 Specimens of coated

\subsection{Waterproofing}

When the percentages of DPET content increase, the percentages of water absorption decrease. The waterproofing in the concrete coated with modified asphalt is more than the uncoated one, but due the temperature increases the porosity of modified asphalt will go bigger as a result of stretching. This leads to increasing in the penetration and absorption, consequently leading to increase the need for more $\%$ DPET in the coating. Figure (13) shows the values of water absorption of different percentages of DPET content for various ranges of temperatures agreed with Iraq weather.

\section{Conclusions}

In this work the results are going to be useful and helpful in the road paving and coating applications by waste plastics recycling, So the following conclusion could be listed:

1. Waste plastic can improve the waterproofing and performance of roads.

2. The cost of materials used in this research is reduced because the cheapness and affordability of the materials.

3. The DPET additives show a great improvement in asphalt specification in terms of the flow, stability, bulk density, and air voids.

4. The coating with DPET modified asphalt has shown that the percentage of water absorption has decreased at various temperature ranges in Iraq.

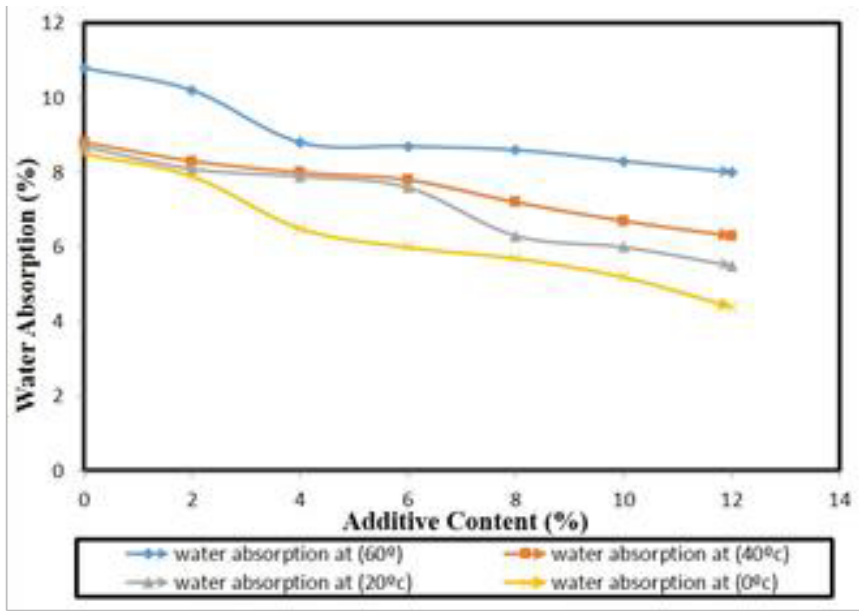

Fig. 13 DPET effects on water absorption of Asphalt mixture different temperature.

\section{References}

1. M. Alzuhairi, A.Al-Ghaban, S. N. Almutalabi. "Chemical Recycling of Polyethylene Terephthalate (PET) as Additive for Asphalt." ZANCO J. of Pure and Applied Sciences. 28, 2; 675-679 (2016).

2. M. Sulyman, Haponiuk, K. Formela "Utilization of Recycled Polyethylene Terephthalate (PET) in Engineering Materials: A Review." Int. J. of Envir. Sc. and Develop., 7, 2, 100. (2016).

3. W. Aishah, S. Mohd Rawi, and N. Desa, "Utilization of Plastic Bottle Waste in Sand Bricks." J. of Basic and Applied Scientific Research, 2090-4304 (2015). 
4. T.. Mathew,"Pavement materials: Bitumen" Lecture notes in Transportation Systems Engineering, (2009).

5. S. AbdulWahab, Iraqi specification for Roads and Bridges, Planning Ministry Centeral of Orgnization for Standerization and Quility Control (2016).

6. Mosadeghzad, et al."Preparation and properties of acacia sawdust/UPR composite based on recycled PET"; Malaysian Polym. J., 4, 1, 30-34 (2009).

7. M. Alzuhairi,, K. Shabbeb, S. Alsa,edy, "Heat and Chemical Treatments for Sawdust/UPE Composites", Eng. \& Tech. J., 34 Part (A),.8 (2016).

8. F. Awaja and D. Pavel, "A Review of Recycling of PET" Eur. Polym. J., 41, 1453- 1477 (2005).

9. D. Torre, "Feasibility overview of a solar water heater made of polyethylene terephthalate bottles for rural areas in Guatemala.", Institute of Science and Technology for Development, Rafael Landivar University, (2011).

10. A. Raheem, and L. Uyigue, "The conversion of post-consumer PolyEthylene Terephthalate (PET) into a thermosetting polyester resin." Arch. Appl. SCI. Res 2 240-254. (2010).

11. A. Mohammad, and L. Shbeeb, "The use of polyethylene in hot asphalt mixtures." American Journal of Applied Sciences 4, 6 390-396. (2007). 